\title{
Investigation of the Notable Maneuvers of a Low-speed Air Platform to Get Away from Surface-to-Air Threats
}

\author{
Bülent Özkan ${ }^{1 *}$ \\ 1* Gazi University, Faculty of Engineering, Mechanical Engineering Department, Ankara, Turkey, (ORCID: 0000-0003-3112-9723), bozkan@,gazi.edu.tr
}

(1st International Conference on Applied Engineering and Natural Sciences ICAENS 2021, November 1-3, 2021)

(DOI: 10.31590/ejosat.1006607)

ATIF/REFERENCE: Özkan, B. (2021). Investigation of the Notable Maneuvers of a Low-speed Air Platform to Get Away from Surface-to-Air Threats. European Journal of Science and Technology, (28), 1167-1171.

\begin{abstract}
The most reasonable attitude in order for low-speed aerial platforms including helicopters and unmanned air vehicles which do not involve any counter measure system to survive is to get away with a convenient maneuver when they are subjected to man-portable surface-to-air rockets and missiles. The mentioned approach may become challenging for low-speed platforms. In this study, the effectiveness of notable escape maneuvers is investigated using relevant computer simulations for a low-speed aerial platform. This way, it is shown that the aerial platforms can escape from surface-to-air threats under the circumstance of lack of any counter measure opportunity.
\end{abstract}

Keywords: Low-speed Air Platform, Unmanned Air Vehicle, Surface-to-air Threat, Missile, Maneuver.

\section{Yerden Gelen Tehditlerden Kaçmak Amacıyla Düşük Hızlı Bir Hava Platformunun Yapabileceği Başlıca Manevraların İncelenmesi}

$\ddot{O} \mathbf{z}$

Yerden havaya doğru firlatılan taşınabilir roket ve füzelerin tehdidi altındaki düşük hızlı ve karşı tedbir sistemi içermeyen helikopter ve insansız hava aracı gibi hava platformlarının bekasını sağlayabilmesi için yapması gereken en anlamlı hareket uygun bir manevrayla kaçmaktır. Bahsedilen yaklaşım, düşük hızlı platformların kapasitesini zorlayıcı bir özelliğe sahiptir. Bu çalışmada, düşük hızlı bir hava platformunun belirtilen kapsamda izleyebileceği belli başlı kaçma manevralarının etkinliği gerçekleştirilen bilgisayar benzetimleri yardımıyla incelenmektedir. Neticede, herhangi bir karşı tedbir olanağına sahip olmayan hava platformlarının yerden havaya fırlatılan mühimmattan kaçabileceği gösterilmektedir.

Anahtar Kelimeler: Düşük Hızlı Hava Platformu, İnsansız Hava Aracı, Yerden Havaya Fırlatılan Tehdit, Füze, Manevra.

\footnotetext{
* Corresponding Author: bozkan@gazi.edu.tr
} 


\section{Introduction}

No matter for civilian or military purpose, low-speed air platforms including helicopters and unmanned air vehicles may sometimes be subjected to threats including the rockets or missiles which are fired from aerial or ground platforms. The man-portable surface-to-air munition constitutes a more dangerous class against low-speed air platforms than other kinds of rockets and missiles because of their high maneuvering capability and low detectability [1], [2]. For the platforms which do not contain any counter measure system, the most reasonable action is to attempt to get away from the threat by a convenient escape maneuver right after the detection of the threat. Although this approach seems inherent behaviour, it may be quite challenging for the platforms regarding their physical capacities [3].

In this study, notable escape maneuvers low-speed air platforms can perform are dealt with against man-portable surface-to-air missiles. The success of the proposed approach is evaluated by means of relevant computer simulations.

\section{Threat Model}

The dynamic behavior of a portable surface-to-air missile which is considered as a threat for the air platform can be defined using the following equations [4]:

$$
\begin{aligned}
& \dot{u}-r v+q w=\left(X+X_{T}\right) / m+g_{x} \\
& \dot{v}+r u-p w=\left(Y+Y_{T}\right) / m+g_{y} \\
& \dot{w}-q u+p v=\left(Z+Z_{T}\right) / m+g_{z} \\
& \dot{p}=L / I_{m a} \\
& \dot{q}-p r=\left(M+M_{T}\right) / I_{m t} \\
& \dot{r}+p q=\left(N+N_{T}\right) / I_{m t}
\end{aligned}
$$

For the longitudinal, lateral, and vertical components of the relevant vectors in the missile-fixed reference frame $\left(F_{b}\right)$, the forthcoming definitions are introduced:

$m$ : Mass of the missile

$I_{m a}$ and $I_{m t}$ : Longitudinal and lateral moment of inertia components of the missile

$p, q$, and $r$ : Components of the angular velocity vector in the roll, pitch, and yaw directions

$u, v$, and $w$ : Components of the linear velocity vector of the missile

$X, Y$, and $Z$ : Components of the aerodynamic force acting on the mass center of the missile

$L, M$, and $N$ : Components of the aerodynamic moment vector acting on the missile body vector in the roll, pitch, and yaw directions

$X_{T}, Y_{T}$, and $Z_{T}$ : Components of the thrust vector acting on the mass center of the missile

$L_{T}, M_{T}$, and $N_{T}$ : Components of the thrust misalignment moment vector acting on the missile body

$g_{x}, g_{y}$, and $g_{z}$ : Components of the gravity vector acting on the mass center of the missile

Assuming that the angular motion of the missile in the roll plane is nullified by means of the roll autopilot prior to its motion in the pitch and yaw planes, i.e. $p \approx 0$, the equations of motion of the missile can be obtained for the phases after the burnout by regarding equations (2), (3), (5), and (6) in the following manner [4]:

$$
\begin{aligned}
& \dot{w}-q u=(Z / m)+g_{z} \\
& \dot{q}=M / I_{m t} \\
& \dot{v}+r u=(Y / m)+g_{y} \\
& \dot{r}=N / I_{m t}
\end{aligned}
$$

In the present work, it is considered that the missile flies unguided from the firing to the end of the thrust. Afterwards, it passes the intermediate guidance phase in which the inertial guidance is applied till the detection of the aerial platform by its seeker. Finally, the terminal guidance phase begins once the target is detected. Here, it is assumed that the missile is guided by means of the proportional navigation guidance ( $\mathrm{PNG}$ ) law throughout the terminal guidance phase.

The relationships defining the guidance commands generated by the PNG law can be written as follows [5]:

$$
\begin{aligned}
& a_{p}^{c}=-N_{p} v_{M} \dot{\lambda}_{p} \cos \left(\lambda_{y}-\eta_{m}\right) \\
& a_{y}^{c}=N_{y} v_{M}\left[\dot{\lambda}_{y} \cos \left(\gamma_{m}\right)-\dot{\lambda}_{p} \sin \left(\gamma_{m}\right) \sin \left(\lambda_{y}-\eta_{m}\right)\right]
\end{aligned}
$$

where $v_{M}$ indicates the magnitude of the linear velocity vector of the missile while $\gamma_{m}$ and $\eta_{m}$ denote the flight path angles which are the angles of the missile velocity vector with respect to the pitch and yaw planes, respectively. As letters $p$ and $y$ indicate the pitch and yaw planes in sequel, $a_{p}^{c}$ and $a_{y}^{c}$ correspond to the reference signals to the missile control system, i.e. missile autopilot, $N_{p}$ and $N_{y}$ denote the effective navigation ratios, and $\lambda_{p}$ and $\lambda_{y}$ represent the orientation angles of the line-of-sight (LOS) vector with respect to the pitch and yaw planes of the Earth-fixed reference frame $\left(F_{0}\right)[5]$.

In order to realize the guidance commands, the missile control systems, i.e. the missile autopilots, are designed separately in the roll, pitch, and yaw planes. An autopilot basically consists of a controller, control actuation system (CAS), gyros, accelerometers, and plant. In this arrangement, the missile constitutes the plant. In the modeling, the gyros, accelerometers, and CAS are so selected that their operating frequencies are higher than the bandwidth of the autopilots in order for them not to affect the entire missile dynamics [4].

The roll autopilot is designed based on the proportional plus derivative (PD) control action in order to make the roll angle of the missile zero. As being responsible of the control of the missile right after the nullification of the roll angle, the pitch and yaw autopilots are constructed by regarding the proportional plus integral (PI) control action supplemented by the pitch/yaw feedback. The pitch and yaw autopilots consider the components of the linear acceleration vector of the missile in the pitch and yaw planes as control variables. Unlike a frozen-gain control system, the autopilot gains are continuously updated depending on the current values of the $M_{\infty}, p, q, r$, and dynamic pressure in order to guarantee the stability of the missile throughout the engagement [4].

The block diagram of the pitch autopilot which has the same structure as the yaw autopilot is shown in Figure 1. In Figure 1, $a_{z d}, a_{z}$, and $e_{a}$ stand for the desired and actual values of the component of the linear acceleration vector of the missile in the pitch plane, and acceleration error, respectively. Also, $K, T$, and $K_{q}$ denote the proportional, integral, and pitch plane gains of the controller of the pitch autopilot, respectively while $G_{q \delta}(s)$ and $G_{a \delta}(s)$ correspond to the relevant transfer functions. Here, the 
controller gains are calculated using the known pole placement technique as per the specified bandwidth and damping ratio values of the autopilot [4].

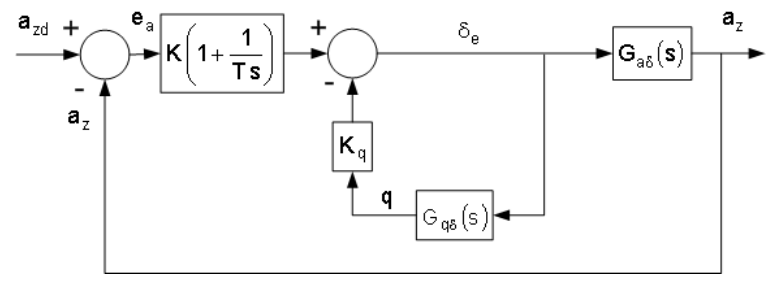

Figure 1. Block Diagram of the Pitch Autopilot [4]

\section{Air Platform Model}

Once the normal and tangential components of the linear acceleration vector of the air platform in $F_{0}$, i.e. $a_{P}^{n}$ and $a_{P}^{t}$, are designated as well as the initial values of its linear speed and orientation angle, i.e. $v_{P 0}$ and $\eta_{p o}$, the linear speed and orientation angle of the platform, i.e. $v_{P}$ and $\eta_{p}$ can be expressed depending on time as below polynomial [4]:

$v_{P}(t)=v_{P 0}+\int_{t_{0}}^{t} a_{P}^{t}(\sigma) d \sigma$

$\eta_{p}(t)=\eta_{p t 0}+\int_{t_{0}}^{t} \frac{a_{P}^{n}(\sigma)}{v_{P}(\sigma)} d \sigma$

where $t_{0}$ demonstrates the initial time of the missile-target engagement and symbol $\sigma$ denotes the dummy integration variable.

Using equations (13) and (14), the longitudinal, lateral, and vertical components of the linear position vector of the platform in $F_{0}$, i.e. $x_{P}, y_{P}$, and $z_{P}$, can be expressed in the next manner as $x_{P 0}, y_{P 0}$, and $z_{P 0}$ show the values of the linear position components at the beginning of the engagement [4]:

$x_{T}(t)=x_{T 0}+\int_{t_{0}}^{t} v_{T}(\sigma) \cos \left(\eta_{t}(\sigma)\right) d \sigma$

$y_{T}(t)=y_{T 0}+\int_{t_{0}}^{t} v_{T}(\sigma) \sin \left(\eta_{t}(\sigma)\right) d \sigma$

$z_{T}(t)=f(t)$

where $f(t)$ denotes a function changing in time.

\section{Engagement Geometry between the Air Platform and Threat}

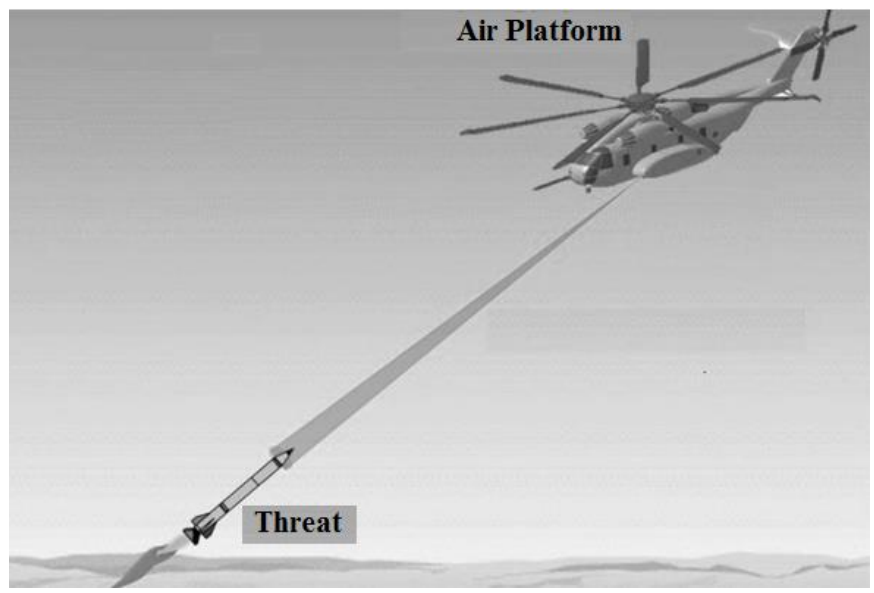

Figure 2. Engagement between the Air Platform and Threat
The engagement and related geometry between the air platform and surface-to-air threat are given in Figure 2 and Figure 3, respectively. In Figure 3, letters $O, M$, and $P$ demonstrate the origin of $F_{0}$, threat, or missile, and air platform, respectively. Moreover, $\vec{u}_{i}^{(0)} \quad(i=1,2$, and 3 ) correspond to the unit vectors indicating the longitudinal, lateral, and vertical axes of $F_{0}$, i.e. $x$, $y$, and $z$. Also, $\vec{r}_{M / O}, \vec{r}_{P / O}$, and $\vec{r}_{P / M}$ stand for the linear position vectors of the missile and target relative to point $O$, and linear position vector of the platform relative to the missile, respectively.



Figure 3. Engagement Geometry between the Air Platform and Threat

In addition to the magnitude of the LOS vector, i.e. $r_{T / M}$, the LOS angles which are the angles of the LOS vector with respect to the pitch and yaw planes, i.e. $\lambda_{p}$ and $\lambda_{y}$, can be formulated as given below [4]:

$r_{T / M}=\sqrt{\Delta x^{2}+\Delta y^{2}+\Delta z^{2}}$

$\lambda_{p}=\arctan \left[-\Delta z \cos \left(\lambda_{y}\right) / \Delta x\right]$

$\lambda_{y}=\arctan (\Delta y / \Delta x)$

Expressing the linear position vectors of the platform and threat relative to point $O$ as $\vec{r}_{P / O}=x_{P} \vec{u}_{1}^{(0)}+y_{P} \vec{u}_{2}^{(0)}+z_{P} \vec{u}_{3}^{(0)}$ and $\vec{r}_{M / O}=x_{M} \vec{u}_{1}^{(0)}+y_{M} \vec{u}_{2}^{(0)}+z_{M} \vec{u}_{3}^{(0)}$, the forthcoming relative position components are defined in equations (18) through (20):

$\Delta x=x_{M}-x_{P}$
$\Delta y=y_{M}-y_{P}$
$\Delta z=z_{M}-z_{P}$

In the present work, the time elapsed from the initiation to the termination of the engagement, i.e. from $t_{0}$ to $t_{F}$, is called the engagement time.

\section{Computer Simulations}

The computer simulations are conducted for the constructed air platform-threat engagement geometry by regarding the numerical values submitted in Table 1 for the significant platform and threat parameters using the MATLAB ${ }^{\complement}$ Simulink $^{(}$software under the following conditions:

- ODE 45 differential equation solver is used.

- Operating frequency of the guidance loop is assigned to be $1 \mathrm{~Hz}$.

- It is assumed that the threats, or surface-to-air missiles, are fired towards the air platform at a relative distance of 2,000 to $3,000 \mathrm{~m}$.

- Apart from its constant-speed motion with $v_{M 0}$ as given in Table 1 , the air platform is assumed to move with 
normal accelerations of $0.5 \mathrm{~g}$ and $-0.5 \mathrm{~g}\left(\mathrm{~g}=9.81 \mathrm{~m} / \mathrm{s}^{2}\right)$ with an initial speed of $v_{M O}$ as well.

- Aerodynamic coefficients are computed by regarding $M_{\infty}$ between 0.3 and 2.7, and taking $\delta_{e}$ and $\delta_{r}$ between -10 and $10^{\circ}$. Also, the range between -17 and $19^{\circ}$ is regarded for $\alpha$ and $\beta$.

- Lateral acceleration limit of the missile is regarded to be $\pm 30 \mathrm{~g}$.

- Missile is supposed to be on the LOS at the beginning of the engagement.

- Total angular excursion of each control fin is limited to $\pm 20^{\circ}$.

- Simulations are terminated when the relative distance between the platform and threat drops below $2 \mathrm{~m}$.

The block diagram of the engagement geometry between the air platform and threat is given in Fig. 4. Moreover, the resulting engagement geometries between the air platform and threat are submitted in Figure 5 through Figure 10.

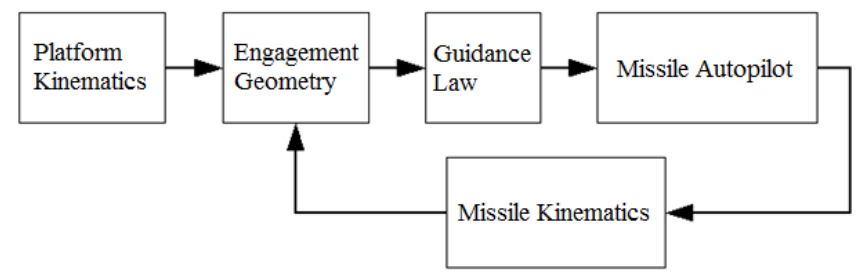

Figure 4. Block Diagram of the Engagement Geometry between the Air Platform and threat

Table 1. Numerical Values used in the Computer Simulations [3], [5]

\begin{tabular}{l|c}
\hline Parameter & Numerical Value \\
\hline$x_{P 0}$ & $1,500 \mathrm{~m}$ \\
\hline$y_{P 0}$ & $50 \mathrm{~m}$ \\
\hline$z_{P 0}$ & $1,500 \mathrm{~m}$ \\
\hline$v_{P 0}$ & 0 \\
\hline$x_{M 0} / \mathrm{s}(\approx 120 \mathrm{~km} / \mathrm{hr})$ \\
\hline$y_{M 0}$ & 0 \\
\hline$z_{M 0}$ & $00 \mathrm{~m} / \mathrm{s}(=1,800 \mathrm{~km} / \mathrm{hr})$ \\
\hline$v_{M 0}$ & $70 \mathrm{~mm}$ \\
\hline Missile Diameter & $2,000 \mathrm{~mm}$ \\
\hline Missile Length & $17.55 \mathrm{~kg}$ \\
\hline$m$ & $0.02 \mathrm{~kg} \cdot \mathrm{m}^{2}$ \\
\hline$I_{m a}$ & $5.85 \mathrm{~kg} \cdot \mathrm{m}^{2}$ \\
\hline$I_{m t}$ & 3 \\
\hline$N_{p}$ and $N_{y}$ & \\
\hline
\end{tabular}

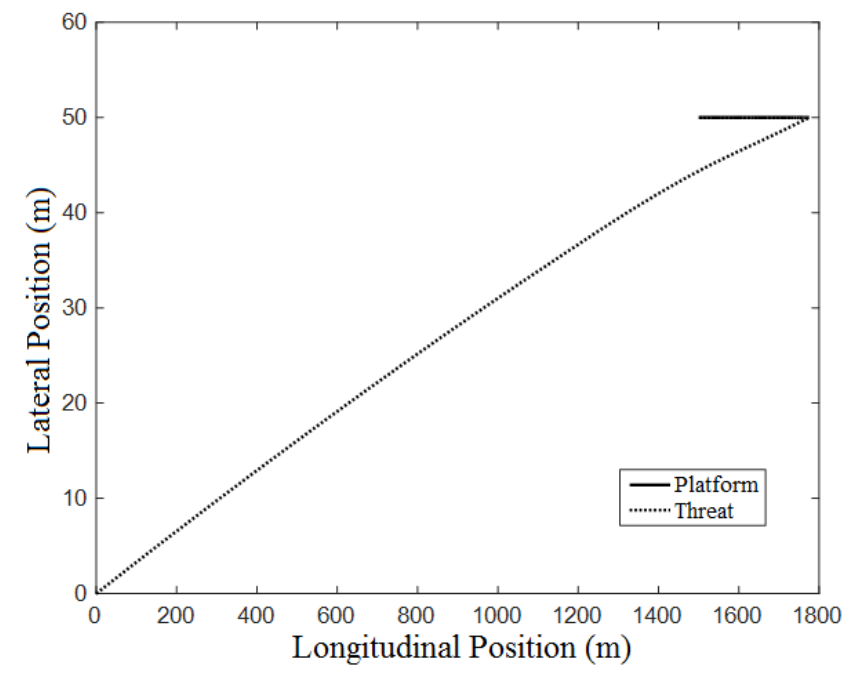

Figure 5. Horizontal Engagement Geometry When the Air Platform Moves at a Constant Speed

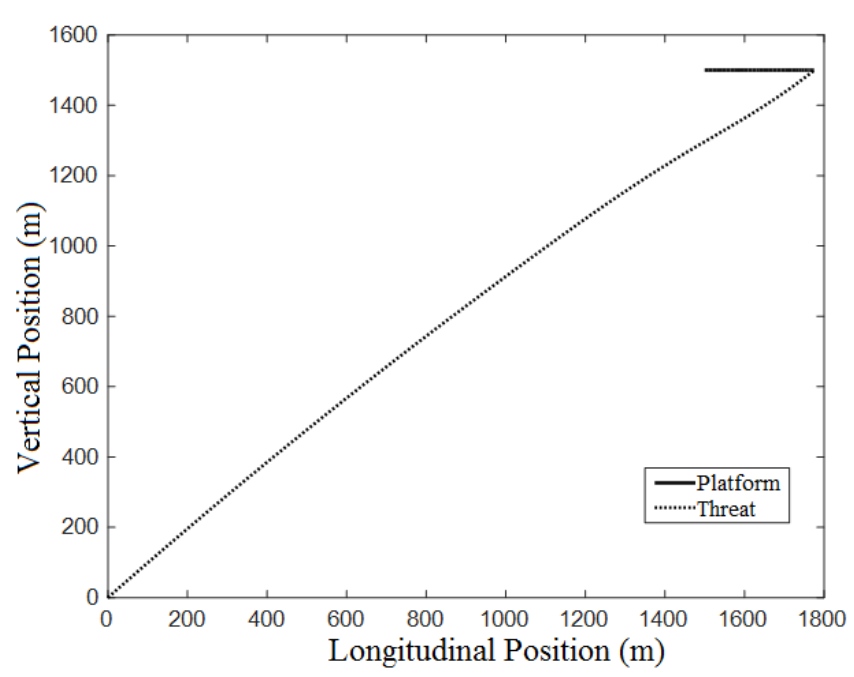

Figure 6. Vertical Engagement Geometry When the Air Platform Moves at a Constant Speed



Figure 7. Horizontal Engagement Geometry When the Air Platform Maneuvers at a Normal Acceleration of $0.5 \mathrm{~g}$ 


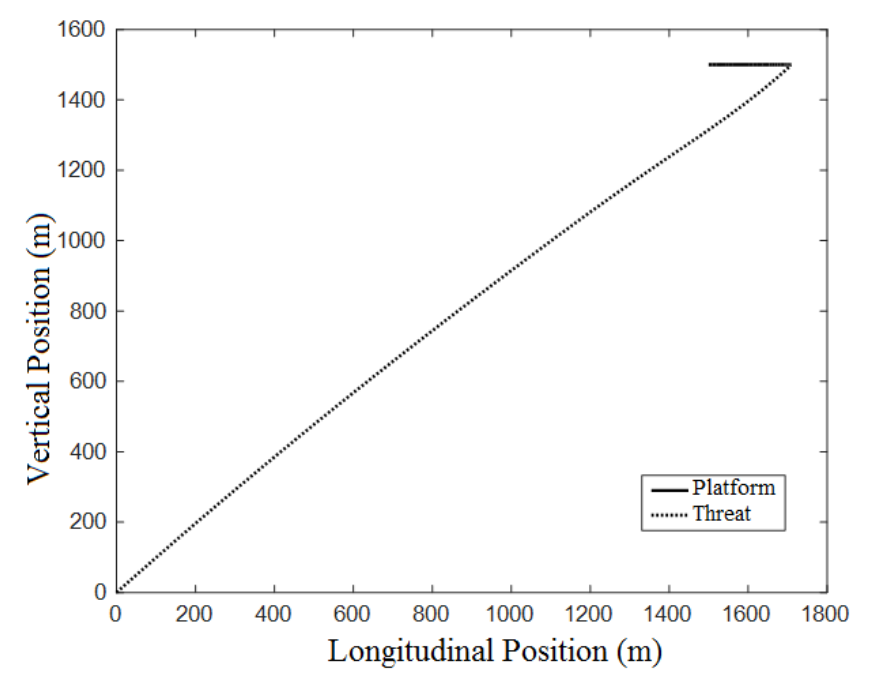

Figure 8. Vertical Engagement Geometry When the Air Platform Maneuvers at a Normal Acceleration of $0.5 \mathrm{~g}$

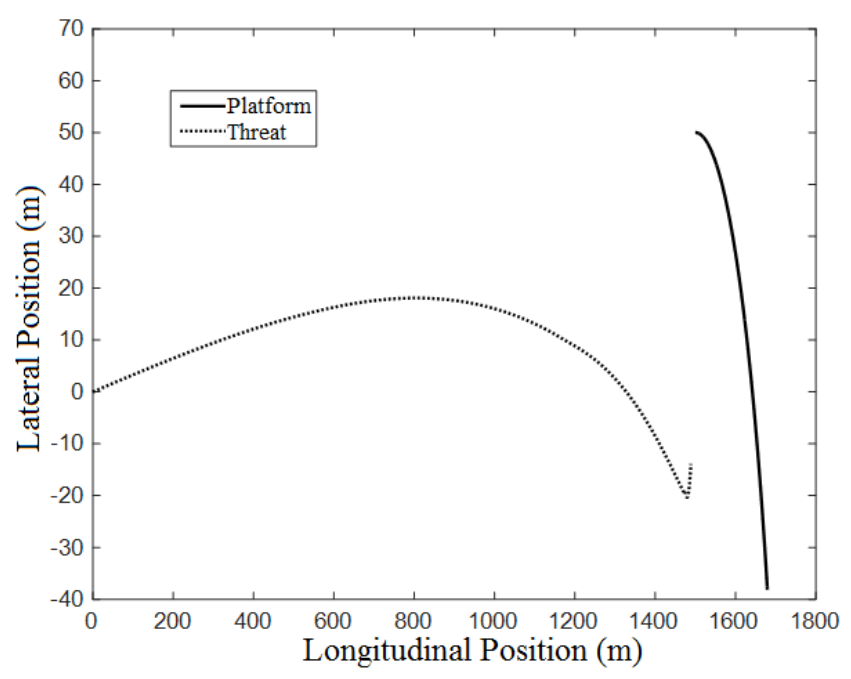

Figure 9. Horizontal Engagement Geometry When the Air Platform Maneuvers at A Normal Acceleration of $-0.5 \mathrm{~g}$

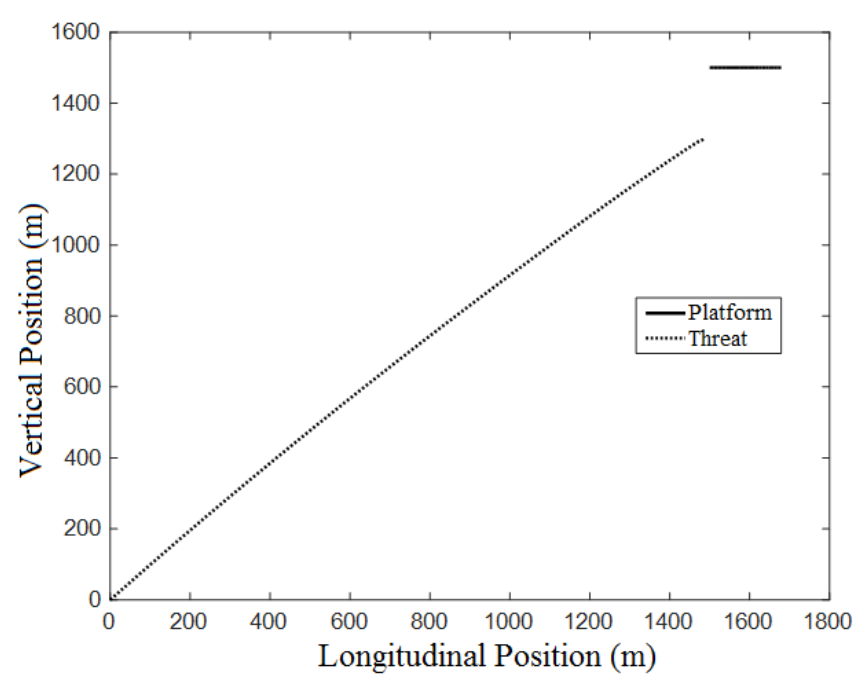

Figure 10. Vertical Engagement Geometry When the Air Platform Maneuvers at a Normal Acceleration of $-0.5 \mathrm{~g}$

\section{Conclusions}

When the plots presented in Figure 5 through Figure 10 are examined, it is deduced that the air platform under consideration cannot escape from the threat fired from the surface if it moves at a constant speed and with a lateral acceleration of $0.5 \mathrm{~g}$. On the other hand, it can get away from the threat if it has a maneuver in the opposite direction at $-0.5 \mathrm{~g}$. This way, it is observed that such an air platform can be disengaged from the threats by applying a convenient maneuver even if it does not carry a counter measure system.

\section{References}

[1] S. Chapman, The Next Generation in Aircraft Protection against Advanced MANPADS, 2014.

[2] W. Xin, L. Guofang, and X. Lizhong, X., "Infrared dim target detection based on visual attention", Infrared Physics \& Technology, vol. 55, pp. 513-521, 2012.

[3] B. Özkan, "Investigation of the kinematic performance characteristics of an antenna orientation mechanism utilized on a general-purpose aerial platform for threat detection (in Turkish)", 18th National Machine Theory Symposium (UMTS2017), Karadeniz Technical University, Trabzon, Turkey, 2017.

[4] B. Özkan, M. K. Özgören and G. Mahmutyazıcıŏlu, "Comparison of the acceleration- and angle-based guidance laws for a short-range air-to-surface missile (in Turkish)", Automatic Control National Meeting in 2008 (TOK2008), İstanbul Technical University, İstanbul, Turkey, 2008.

[5] B. Özkan, "Dynamic modeling, guidance, and control of homing missiles", PhD Thesis, Middle East Technical University, Ankara, Turkey, 2005. 